\title{
A pediatric case of rhabdomyolysis with acute renal failure due to co-infection with Epstein-Barr virus and Human herpesvirus 6
}

\author{
Marina Attanasi, Marianna Immacolata Petrosino, Paola Irma Guidone, Daniele Rapino, \\ Laura Comegna, Nadia Rossi, Annalisa Blasetti, Francesco Chiarelli
}

Department of Pediatrics, Allergy and Respiratory Diseases Clinic, University of Chieti, Chieti, Italy

Submitted: 14 May 2015

Accepted: 28 October 2015

Arch Med Sci 2018; 14, 1: 254-256

DOI: 10.5114/aoms.2016.61352

Copyright @ 2016 Termedia \& Banach

Rhabdomyolysis is a syndrome characterized by muscle breakdown and necrosis resulting in leakage of the intracellular muscle constituents into the circulation and extracellular fluid. It ranges from an asymptomatic illness with elevation in creatine phosphokinase (CK) levels to a life-threatening condition characterized by electrolyte imbalances, acute kidney injury (AKI) and disseminated intravascular coagulation [1].

One of the most common etiologies of rhabdomyolysis in the pediatric population is viral $[2,3]$. We report a rare childhood case of rhabdomyolysis associated with a dual viral infection. Epstein-Barr virus (EBV) was identified serologically and Human herpesvirus 6 (HHV6) was individualized with quantification of DNA by real-time polymerase chain reaction (DNA PCR).

Informed consent of the patient's parents was obtained.

A 22-month-old child was admitted to the Pediatrics Department (University of Chieti) for incoercible vomiting (about 10 episodes in the past $12 \mathrm{~h}$ ) and inappetence. She had a history of malaise, sore throat and irritability for about 2 days. There was no family history of renal, musculoskeletal or metabolic diseases. She did not take drugs in the previous 2 weeks before the admission. The child's mother reported a head injury by falling out of bed $24 \mathrm{~h}$ before. For this reason an urgent brain computed tomography scan was performed, showing no abnormalities. Physical examination was normal: blood pressure 108/67 mm Hg, pulse rate 115 beats/min and temperature $36^{\circ} \mathrm{C}$. Chest and cardiac auscultation were normal, while the abdomen was widely painful. There were no evident signs of myopathy. Some small axillary and inguinal lymph nodes were palpated. Liver and spleen were not enlarged. Blood work revealed lactate dehydrogenase $2988 \mathrm{U} / \mathrm{l}(\mathrm{N}: 313-618 \mathrm{U} / \mathrm{l})$, creatine phosphokinase $2443 \mathrm{U} / \mathrm{l}(\mathrm{N}: 30-135 \mathrm{U} / \mathrm{l})$, aspartate aminotransferase $898 \mathrm{U} / \mathrm{l}$ $(\mathrm{N}: 14-36 \mathrm{U} / \mathrm{l})$, alanine aminotransferase $2135 \mathrm{U} / \mathrm{l}(\mathrm{N}: 19-52 \mathrm{U} / \mathrm{l})$ and myoglobin $1510.0 \mathrm{ng} / \mathrm{ml}(\mathrm{N}:$ 9.0-82.5 U/l), consistent with skeletal muscle necrosis. No measurement of myoglobin in urine was performed. White blood cells count was $10.25 \times 10^{3} / \mu \mathrm{l}\left(\mathrm{N}: 4-10 \times 10^{3} / \mu \mathrm{l}\right)$ with $51 \%$ neutrophils, $39.5 \%$ lymphocytes and $8.3 \%$ monocytes. Following the admission the child had impaired renal function: serum creatinine level was $2.60 \mathrm{mg} / \mathrm{dl}(\mathrm{N}$ : 0.52-1.04), urea $87 \mathrm{mg} / \mathrm{dl}(\mathrm{N}: 7-17)$, sodium $131 \mathrm{mmol} / \mathrm{l}(\mathrm{N}:$ 133-145), potassium $5.6 \mathrm{mmol} / \mathrm{l}$ (N: 3.60-5.50), calci-

\author{
Corresponding author: \\ Marina Attanasi MD \\ Department of Pediatrics, \\ Allergy and Respiratory \\ Diseases Clinic \\ University of Chieti \\ Via dei Vestini 5 \\ 66100 Chieti, Italy \\ Phone: +39 3200564453 \\ E-mail:marina attanasi@ \\ hotmail.it
}


um $2.30 \mathrm{mmol} / \mathrm{l}(\mathrm{N}: 2.10-2.55)$ and magnesium $2.5 \mathrm{mg} / \mathrm{dl}(\mathrm{N}: 1.6-2.3)$. At the admission urine dipstick revealed glucose $1+$, protein $2+$ and blood $3+$, and urine analysis showed proteinuria $(50 \mathrm{mg} / \mathrm{dl})$. The inflammatory markers were also elevated (C-protein reactive of $6.01 \mathrm{mg} / \mathrm{dl}$ $(\mathrm{N}:$ 0.00-0.50) and erythrocyte sedimentation rate of $16 \mathrm{~mm} / \mathrm{h}$ ( $\mathrm{N}: 1-15)$ ). Venous blood gas analysis showed $\mathrm{pH} 7.35, \mathrm{pCO}_{2} 23.5 \mathrm{~mm} \mathrm{Hg}, \mathrm{pO}_{2}$ $34.7 \mathrm{~mm} \mathrm{Hg}$, bicarbonate $11.9 \mathrm{mmol} / \mathrm{l}$. The metabolic evaluation (acylcarnitines and organic acids) was normal. Other biochemical and hematological laboratory values were in the normal range. A chest radiograph and electrocardiogram were normal. Blood and urine cultures were negative. Serology for Influenzavirus types A and B, hepatitis A, B and C viruses, Adenovirus, Mycoplasma pneumoniae, Chlamydia spp., parainfluenza viruses types 1, 2 and 3, Toxoplasma gondii, Rubella virus, Herpesvirus 1 and 2, Cytomegalovirus and respiratory syncytial virus was all negative. In contrast, EBV immunoglobulin $M$ (IgM) and IgG were elevated $(76.1 \mathrm{U} / \mathrm{ml}$ and $26 \mathrm{U} / \mathrm{ml}$, respectively ( $\mathrm{N}: 0-20.0$ $\mathrm{U} / \mathrm{ml})$ ), suggesting a recent infection. Furthermore, DNA PCR showed positivity for HHV6, document- ing the coexistence of another viral infection. The clinical conditions were stable, except for some episodes of vomiting and diarrhea. However, the child appeared plaintive and she refused to walk. Blood tests at $22 \mathrm{~h}$ from admission documented worsening of creatinine values $(3.60 \mathrm{mg} / \mathrm{dl})$, an increase of potassium blood levels $(6.3 \mathrm{mmol} / \mathrm{l})$ and a peak of creatine phosphokinase $(6.723 \mathrm{U} / \mathrm{l})$. The clinical and laboratory findings were suggestive of rhabdomyolysis with AKI. Despite immediate and vigorous hydration with saline solution and urine alkalization with sodium bicarbonate, the patient developed non-oliguric acute renal failure requiring the transfer to the Pediatric Nephrology Department for further treatment options. Kayexalate (sodium polystyrene sulfonate) and oral calcium gluconate were administered for hyperkalemia. Heart rate, pulse oximetry, blood pressure and diuresis remained stable. For this reason, hemodialysis was not necessary. During hospitalization the patient presented a rapid decline in the serum CK level (Figure 1), gradual disappearance of fatigability and muscle weakness with a complete recovery of renal function 10 days after the onset of therapy. Noticeably, the serum CK and

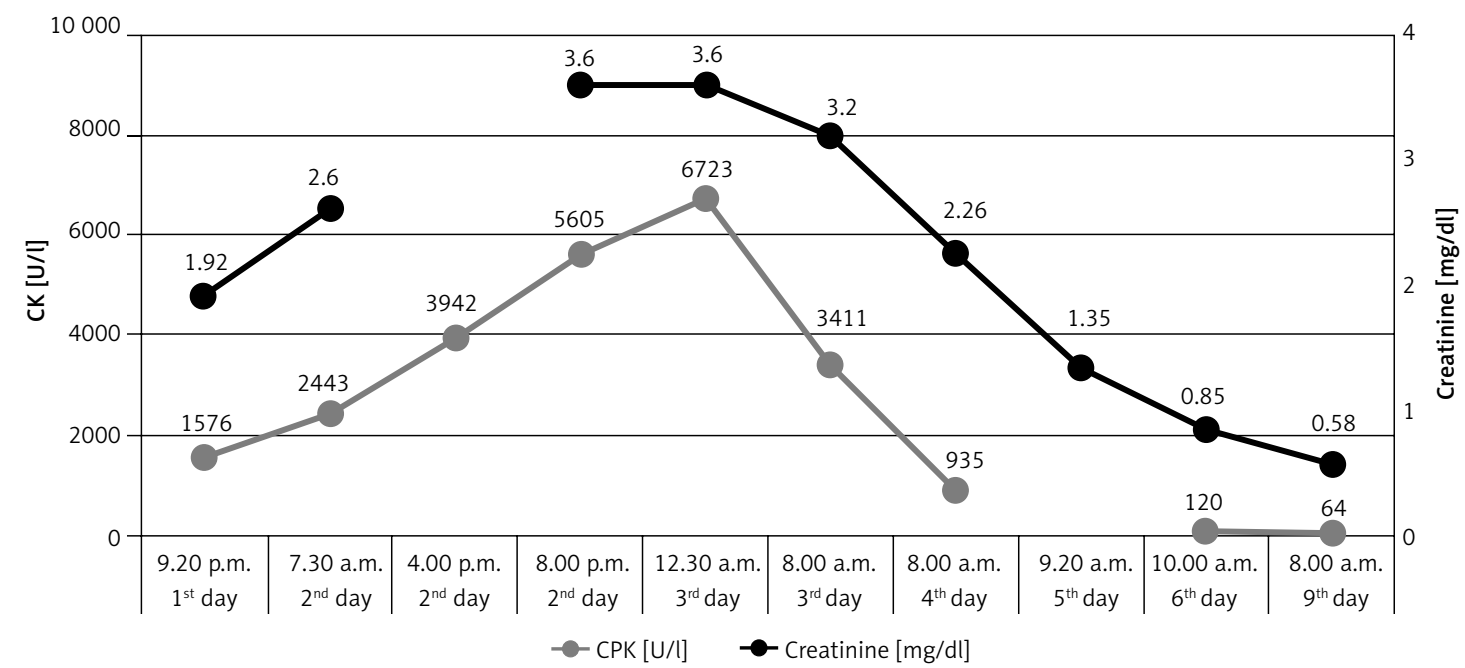

Figure 1. Time variation of serum creatine phosphokinase (CK) and creatinine levels

A

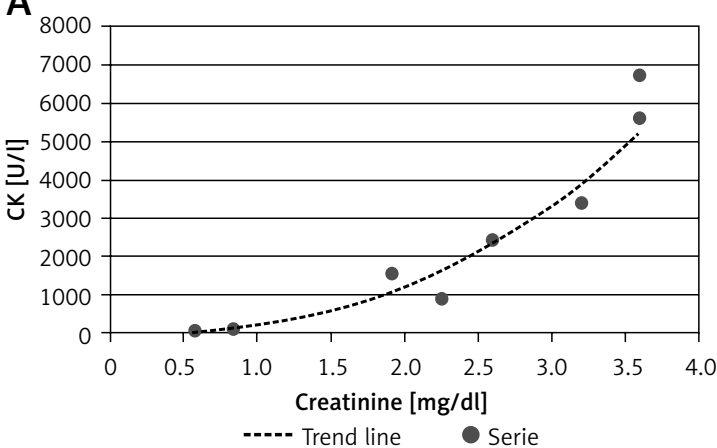

B

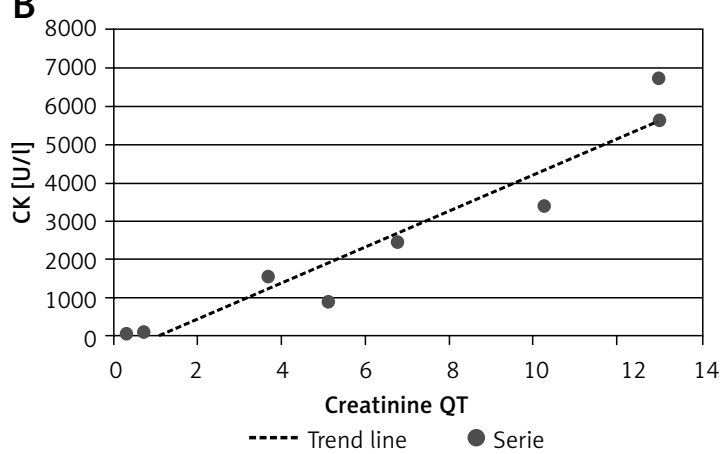

Figure 2. A - Relationship between serum creatine phosphokinase (CK) and creatinine levels (Pearson's correlation, $r=0.90, p=0.002)$, B - quadratic transformation of creatinine values $(r=0.96, p<0.001)$ 
creatinine levels demonstrated the same trend (Figure 1). In addition, we found a direct correlation between CK and creatinine levels (Figure $2 \mathrm{~A}$, Pearson's correlation, $r=0.90, p=0.002$ ). This correlation was significantly increased after quadratic transformation of creatinine values (Figure $2 \mathrm{~B}$, $r=0.96, p<0.001)$.

In this case the presence of prodromal and gastrointestinal symptoms and increased inflammatory markers in a first episode of rhabdomyolysis suggest viral infectious etiology, confirmed by the increased EBV IgM and the presence of HHV6 DNA by PCR (bioMérieux ARGENE, kit ref. 69-100B CMV, HHV6,7,8 R-gene, target gene U57). Whether any relation exists between HHV6 and EBV infections and the contribution of EBV to the pathogenesis of the attack of rhabdomyolysis remain unclear. In the literature in children rhabdomyolysis has been reported to be associated with EBV in a few cases $[4,5]$ and with HHV6 infection in a single case [6].

In conclusion, to our knowledge this is the second pediatric case in which the cause of rhabdomyolysis is a co-infection. In our patient a direct effect of EBV on muscle has not been assessed. We might hypothesize that EBV, infecting usually in childhood or early adolescence [7], altered the patient's immune system, allowing the HHV6 infection. In this way HHV6 might have invaded directly into muscle tissue and caused the rhabdomyolysis. The same mechanism may have played a part in the dual infection with EBV and echovirus 6 in the case reported by Poels et al. [8]. These infections might have interacted synergistically.

In addition, we would like to emphasize that increased CK levels could be predictive of renal damage. In clinical practice this finding is of great interest for the management of the patient with rhabdomyolysis.

\section{Conflict of interest}

The authors declare no conflict of interest.

\section{References}

1. Huerta-Alardin AL, Varon J, Marik PE. Bench-to-bedside review: rhabdomyolysis - an overview for clinicians. Crit Care 2005; 9: 158-69.

2. Elsayed EF, Reilly RF. Rhabdomyolysis: a review, with emphasis on the pediatric population. Pediatr Nephrol 2010; 25: 7-18.

3. Mannix R, Tan ML, Wright R, Baskin M. Acute pediatric rhabdomyolysis: causes and rates of renal failure. Pediatric 2006; 118: 2119-25.

4. Friedman BI, Libby R. Epstein-Barr virus infection associated with rhabdomyolysis and acute renal failure 1986; 25: 228-9.

5. Mayer HB, Wanke CA, Williams M, Crosson AW, Federman M, Hammer SM. Epstein-Barr virus-induced infec- tious mononucleosis complicated by acute renal failure: case report and review 1996; 22: 1009-18.

6. Fujino M, Ohashi M, Tanaka K, Kato T, Asano Y, Yoshikawa T. Rhabdomyolysis in an infant with primary human herpesvirus 6 infection. Clin Pediatr 1986; 25: 228-9.

7. Khabaz MN. Association of Epstein-Barr virus infection and breast carcinoma. Arch Med Sci 2013; 9: 745-51.

8. Poels PJ, Ewals JA, Joosten EM, Van Loon AM. Rhabdomyolysis associated with simultaneous Epstein-Barr virus infection and isolation of echovirus 6 from muscle: a dual infection. J Neurol Neurosurg Psychiatry 1989; 52: $412-4$ 